\title{
STUDIES ON INFLAMMATION
}

\author{
XIV. Isolation of the Factor Concerned with InCreased \\ Capillary Permeability in Injury* $\dagger$ \\ By VALY MENKIN, M.D. \\ (From the Department of Pathology, The Harvard Medical School, Boston) \\ Plate 3 \\ (Received for publication, September 22, 1937)
}

Previous studies have indicated the presence in various types of exudate of a factor, which, when brought in contact with normal capillaries, induces a prompt increase in filtration through the endothelial wall $(1,2)$. This is readily demonstrated by the local seepage into treated cutaneous areas of an intravenously injected dye, e.g. trypan blue. This factor does not exhibit the properties of histamine. Histamine either fails to induce an increase in the permeability of the capillaries of the rabbit, as demonstrated by the methods utilized, or else the increase is limited solely to the periphery of the treated cutaneous areas (2). Furthermore, no concrete evidence was obtained to support the view of an existing histamine-like substance in exudates or in their partially purified active fraction. The possibility, however, that histamine exists in exudates is not wholly dispelled by the available evidence on the presence of the permeability factor; but the primary importance of histamine in explaining the mechanism of increased capillary permeability in inflammation is open to doubt.

The studies have been continued in an endeavor to isolate and purify the active permeability factor. Its liberation and consequent pres-

\footnotetext{
* Read before the American Association of Pathologists and Bacteriologists, March 25, 1937, at Chicago.

$\dagger$ Aided by grants from the Milton Fund of Harvard University, the Permanent Charity Fund and the Wellington Memorial Research Fund of The Harvard Medical School, the Committee for Scientific Research and the Council of Pharmacy and Chemistry, American Medical Association, and from the International Cancer Foundation.
} 
ence in exudates would offer a reasonable explanation for the increased passage of fluid from the circulating blood into an inflamed area.

Observations, to be described, indicate that the active factor is a dialyzable, non-protein, nitrogenous crystalline substance. The present evidence points to its being an intermediary product of protein catabolism probably related to the group of simple polypeptides. In an accompanying paper it will be shown that this substance seems to be likewise concerned with the mechanism of leukocytic migration in inflammatory foci.

\section{Purification of the Factor}

Exudates were generally obtained, as described previously, from the pleural cavities of dogs after intrapleural injection with 1 to $2 \mathrm{cc}$. of turpentine (2). The exudate resulting from the intraperitoneal injection of an aleuronat-starch mixture in a rabbit was likewise studied.

The cell-free exudate was treated with an equal volume of pyridine. A heavy flocculating precipitate resulted. The mixture was vigorously shaken for several hours in an electrical stirring apparatus. The material was then centrifugalized at rapid speed. The supernatant layer appeared as a yellowish green fluid, occasionally tinted reddish brown. This fraction, when evaporated in vacuo at about $45^{\circ} \mathrm{C}$. yielded, upon resuspension in saline or distilled water, a substance that readily enhanced normal capillary permeability. Blood serum similarly treated yielded a material that was practically inactive.

Further purification of the active factor was attained by treating the supernatant-pyridine fraction with an equal volume of acetone. ${ }^{1}$ The resulting heavy greyish precipitate was separated by centrifugalization. The active factor was found primarily in the acetone supernatant fraction. Storing it at $6^{\circ} \mathrm{C}$. or preferably at $-20^{\circ} \mathrm{C}$. for several days, favored the separation of a brownish, flocculating mass. This substance, taken up in distilled water and injected intracutaneously in a rabbit, increased the permeability of skin capillaries, as indicated by the usual test (2).

The acetone supernatant fraction can also be evaporated in vacuo at about $50^{\circ} \mathrm{C}$. The residue consists of a heterogeneous crystalline mass in which one encounters a variable amount of amorphous tarry material. The crystalline material consists of large branch-like crystals, structurally characterized by the presence of a main shaft with spicules projecting laterally on either side. Close,

\footnotetext{
${ }^{1}$ In earlier studies, as described elsewhere (4), the pyridine supernatant fraction was treated with three times its volume of acetone. Subsequently, however, it was found that a significant part of the active material was apparently lost through this procedure. The use of an equal volume of acetone seemed to yield distinctly better results and this concentration was therefore resorted to in all subsequent extractions.
} 
and at times apparently adherent to these crystals, tiny spherical or rod-like doubly refractile granules are found in variable quantities. This acetone-dried residue forms an aqueous suspension, which upon cutaneous inoculation promptly augments the permeability of the capillaries involved.

The active factor is recovered in the dialysate or diffusate several hours after dialyzing the acetone fraction against distilled water. Both the dialyzed material remaining in the cellophane bag and the diffusate upon subsequent evaporation in vacuo yield potent fractions.

Studies were undertaken on the further purification of the active factor as obtained in the acetone residue. du Nouiy (6) pointed out several years ago that the evaporation of serum in a watch glass yields an adsorption complex consisting of sodium chloride and various organic molecules. The sodium salt under such circumstances assumes the appearance of branch-like crystals with similarities to those obtained in the acetone-dried residue of extracted exudates. Furthermore, when the latter is treated with a 10 per cent solution of silver nitrate, a large white precipitate forms, indicating the presence of chlorides. Several determinations of the sodium content of the active acetone residue by the method of Butler and Tuthill (7) revealed the presence of this element in large quantities, approximating 20 per cent of the total weight of the active material.

In an endeavor to free the active factor from sodium chloride impurities several methods were employed, each yielding more or less the same type of active crystalline substance. The procedures may be briefly summarized as follows:

1. The acetone supernatant fraction (Table I, scheme of extraction) of the treated exudate may be heated on an evaporating bath after which it is immediately subjected to cold in a refrigerator either at $6^{\circ} \mathrm{C}$. or preferably at $-20^{\circ} \mathrm{C}$. After 1 to several days, a flocculating mass separates out. This material is removed by filtration and washed with small amounts of distilled water. It appears as a brown, doubly refractive substance in which the branch-like crystals are essentially absent. The chloride reaction is negative. The bulk of the crystalline material consists of clusters of globular or discrete tiny rod-like crystals. This material, when taken up in distilled water, forms a cloudy suspension. It exhibits great potency when introduced intracutaneously. Trypan blue readily accumulates from the circulating blood stream into areas of the skin treated with this material even in dilution of 1 to $100,000 .^{2}$

2 The active material may also be obtained in the form of picrate crystals. The acetone supernatant fraction, heated with an equal volume of a saturated 
2. The active factor can be dissociated so as to be relatively free of sodium chloride admixture by evaporating the acetone supernatant fraction (Table I) at room temperature. Exposing the active material in vacuo, at relatively low temperature, yields after a variable interval a dark brownish syrupy material localized in the center of the watch glass. The periphery of the evaporated mother liquor reveals deposits of branched crystals. The viscous brown fluid in the center is pipetted off into another watch glass and dried in vacuo at slightly elevated temperature. The end-product is principally made up of a large number of small discrete aggregates of doubly refractive granules. In some preparations there separates out a number of elongated needle-like crystals, some of which may cohere and thus assume a rosette-like appearance. The great majority of these, however, tend to be discrete. There are none of the typical branch-like crystals. The chloride reaction with silver nitrate, if at all present, is barely perceptible. The material is very potent in the skin, producing dilatation of capillaries and lymphatics. Trypan blue from the circulating blood stream permeates in abundance into such treated areas and, as will be pointed out in the accompanying report, this is followed by prompt leukocytic infiltration.

3. Dakin demonstrated a number of years ago that, by the use of butyl alcohol as a solvent, certain products of protein hydrolysis may readily be extracted (8). These included the monoamino acids, proline, and the peptide-anhydrides (diketopiperazines). The latter could be conveniently separated from proline by their sparing solubility in alcohol or water. This almost specific extracting capacity of butyl alcohol for intermediary products of proteolytic breakdown was utilized in an endeavor to further purify the permeability factor.

The procedure adopted was as follows: The acetone-dried residue of an exudate was obtained by evaporating in vacuo $50 \mathrm{cc}$. of the supernatant acetone fraction (Table I). This material was taken up with $25 \mathrm{cc}$. of butyl alcohol. The resulting solution was tinted yellow and contained a suspension of fine particles. The active factor was extracted with butyl alcohol by continuous stirring for several hours. A considerable part of the solution evaporated off during the period of extraction. A cream-colored sediment settled at the bottom of the container; the sides of the vessel above the supernatant layer became coated with a crystalline granular material. The solution was centrifugalized to dispose of any suspended granules in the light amber-colored superficial layer. This clear fraction was then carefully pipetted into a watch crystal and evaporated in vacuo at about $50^{\circ} \mathrm{C}$. The dried material revealed the presence of discrete crystalline aggregates,

solution of picric acid yields, after several days in the refrigerator at about $6^{\circ} \mathrm{C}$., a flocculating crystalline material. These picrate crystals, filtered from their mother liquor, appear at first as small clusters of tiny globular, doubly refractive crystalline material. After further drying, discrete needle-like crystals may separate out. This crystalline material induces in the skin both an increased capillary permeability and, as will be pointed out in the accompanying paper, an active migration of leukocytes. 


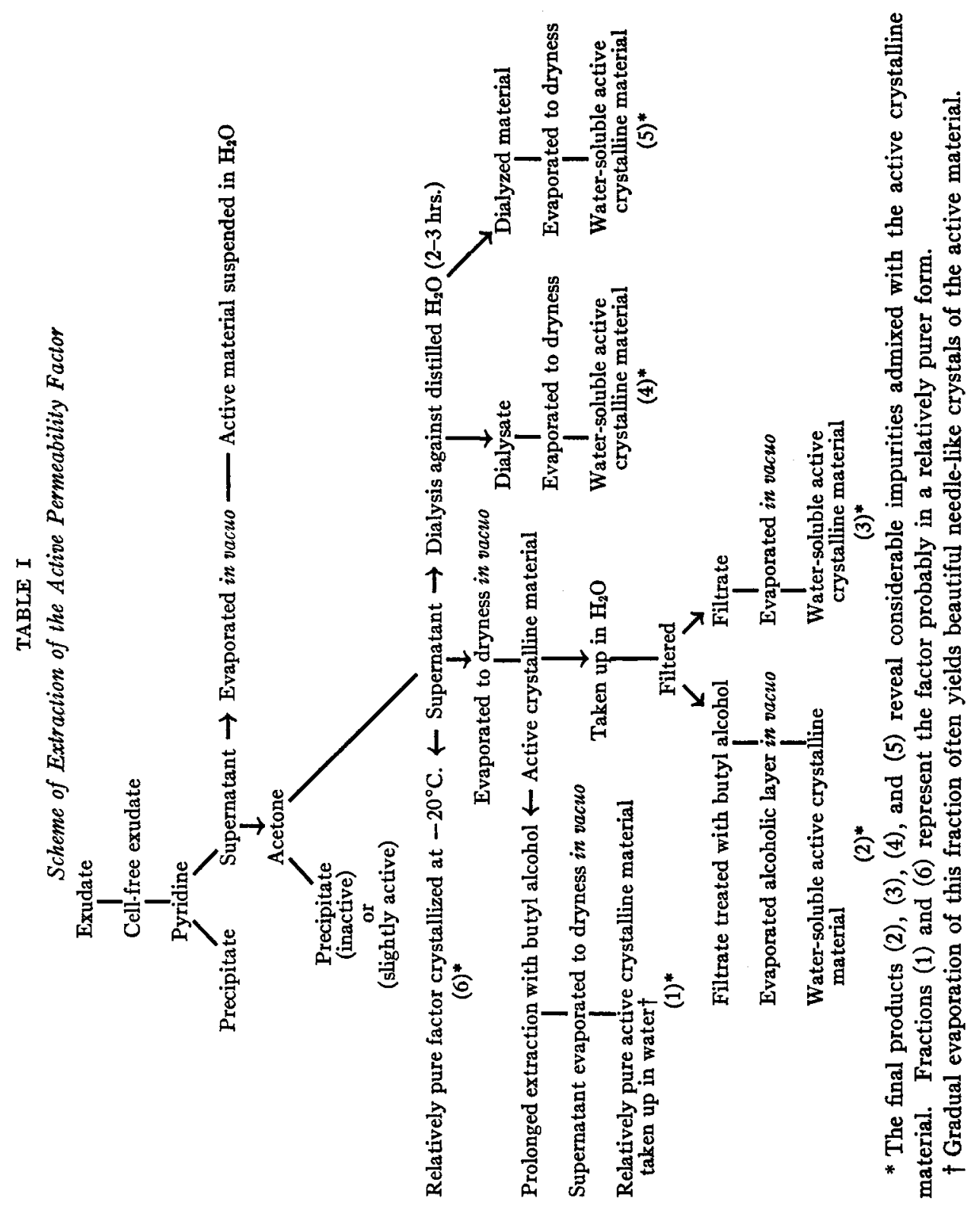


characterized by small clusters of doubly refractive granules. These appeared as if they were bound together by the presence of an ill defined, greyish, homogeneous matrix (Fig. 1). The crystalline material formed a cloudy suspension in water. When the latter was allowed to dry gradually in a desiccator, beautiful needlelike crystals often separated out (Fig. 2). ${ }^{3}$

The crystals, obtained by all three of the methods outlined, appeared to be of similar structure. This was characterized by the formation of discrete aggregates of doubly refractive granules, of needle-like or small rod-like crystals, or of a mixture of both types of crystalline material. The similarity of the end-product attained by different analytical procedures strongly suggests that one is dealing with the same active substance. The crystalline material is extremely active in inducing in treated cutaneous areas of rabbits both increased capillary permeability and leukocytic migration (5). The test for chloride impurities is essentially negative. The sodium content is considerably reduced ( 6.4 per cent). The available evidence indicates that this crystalline substance is in all probability the active permeability factor present in inflammatory exudates, isolated in a form which seems to be relatively free of any gross impurities. ${ }^{4}$

The foregoing procedures have been employed in the further purification of the active material. The butyl alcohol method and the separation at $-20^{\circ} \mathrm{C}$. from the acetone fraction seem to yield the most effective results. The various schemes of extraction employed are summarized in their main features in Table $\mathrm{I}^{\mathbf{6}}$

\footnotetext{
${ }^{3}$ The brownish sediment which settles after butyl alcohol treatment may likewise be active in inducing both increased capillary permeability and leukocytic migration. It contains, however, considerable inorganic impurities such as chlorides.

Furthermore, subjecting the butyl alcohol supernatant fraction for several days at $-20^{\circ} \mathrm{C}$. favors the separation of a fine granular material which per se is usually very effective in increasing capillary permeability and in causing leukocytic migration.

4 Present day methods for testing the chemical purity of proteins or presumably of their derivatives are, as recently pointed out by Northrop, not very satisfactory (11). Studies are now in progress to test the purity of the isolated active permeability factor by applying some of the criteria adopted by Northrop and Kunitz in their own studies.

${ }^{5}$ Repeated treatment with methyl alcohol has not been found to dispose of the excess sodium chloride, inasmuch as the alcohol readily dissolves the combined
} 


\section{Properties of the Factor}

A few of the physical and chemical properties of this active crystalline substance have been described in preliminary communications $(4,5)$. With further purification of the material some additional information has been obtained. The effect of the active material on the isolated strip of guinea pig intestine contrasts sharply with that elicited by histamine. Various physicochemical and biological properties are summarized at this stage, not so much to identify precisely the composition of the permeability factor, but rather in an attempt to provide some lead as to its probable nature. Further studies on its chemical identity will form the subject of future reports.

1. Color and Appearance.-When separated in large measure from inorganic substances by any of the methods described above, the active material appears as a brownish, hydroscopic, doubly refractive crystalline material.

2. Solubility.-When purified, it is relatively insoluble in water, forming a cloudy suspension in this medium. In the presence of acids the material is distinctly more soluble. The aqueous suspension is dissolved, for instance, by the addition of glacial acetic, hydrochloric, or nitric acid. It also appears to be somewhat more soluble in physiological saline than in distilled water. Furthermore, the partially purified active substance, obtained as the acetone-dried residue (Table I), which is probably in large part admixed with sodium chloride, displays greater solubility in water than the purified material. These facts suggest an enhancement of solubility in the presence of electrolytes.

The substance is weakly soluble in acetone. An excess of this organic solvent will precipitate out the active material from the pyridine supernatant fraction (Table I). It is insoluble in ether or absolute alcohol. It is distinctly soluble in methyl and butyl alcohol.

3. Effect of Acid and Alkali.--The material, as prepared, may be either slightly alkaline or slightly acid to phenol red. Its potency is not reduced by keeping it on ice for several weeks, but occasionally its reaction becomes distinctly acid in contrast to an initial alkaline $\mathrm{pH}$. When purified with butyl alcohol, it usually is alkaline to phenol red; whereas in the state in which it is associated with sodium chloride, or in which it is crystallized from the acetone mother liquor at $-20^{\circ} \mathrm{C}$, it tends to be acid in reaction. The reactivity of the active factor does not seem to bear any direct relation to its effect on capillary permeability.

active permeability factor and salt. Repeated treatment with fresh portions of acetone of the acetone-dried residue removes in part the active crystalline factor which can then be recovered in a fairly purified form in the evaporated supernatant layer. 
The contact of this substance for several hours with normal hydrochloric acid does not seem to affect its potency. Similar treatment, however, with normal sodium hydroxide inactivates the material.

4. Effect of Heat or Cold.-The material is thermostable. When brought to $100^{\circ} \mathrm{C}$, it is found still active. When a test tube containing it is placed in boiling water for 15 to 20 minutes, it displays marked activity upon its subsequent intracutaneous inoculation. Heating it in vacuo at $85^{\circ} \mathrm{C}$. for 11 hours has failed to reduce its activity. In a similar fashion, when exposed even for several days at $-20^{\circ} \mathrm{C}$, the material retains full potency.

5. Melting Point.-In its present stage of purification the active material fails to show a sharp melting point. From about $200^{\circ} \mathrm{C}$. or even somewhat below this temperature, to $250^{\circ} \mathrm{C}$. it begins to char; and at $300^{\circ} \mathrm{C}$. it still has not melted. It is well known that a number of proteolytic compounds behave in similar fashion. Greenstein (9), in his recent studies on peptide synthesis, described a similar behavior in the case of the crystalline bisanhydro-l-cystinyl-l-cystine.

6. Diffusibility.-In an earlier communication, it was pointed out that the active permeability factor of exudates readily diffuses through a cellophane membrane (2). As pointed out above, the supernatant acetone fraction containing the active substance may be dialyzed for several hours against distilled water (Table I). Evaporation of both the dialyzed and the dialysate or diffusate fractions reveals the presence of the active crystalline material.

7. Precipitation with Ammonium Sulfate.-The active permeability factor is carried down with the precipitate that forms by the interaction of the exudate with saturated ammonium sulfate (2). Likewise, the addition of the relatively pure fraction of the material to a saturated solution of ammonium sulfate is soon followed by the appearance of a small but definite cloudy suspension. It is interesting to note in this connection that, of the dialyzable proteolytic breakdown products, polypeptides seem to be the only ones that are precipitated by concentrated ammonium sulfate (10).

An attempt was made to determine the effect on the active substance of precipitating it with saturated ammonium sulfate at differing $\mathrm{pH}$ values. It is to be recalled in this connection that Northrop recently succeeded in purifying crystalline enzymes in this way (11). The technique employed by us was as follows:

$30 \mathrm{mg}$. or less of active material obtained in the form of the acetone-dried residue from an exudate (Table I) was treated with $1 \mathrm{cc}$. of a phosphate buffer solution at various $\mathrm{pH}$ concentrations as follows: $5.3,6.8,7.3$, and 7.8. The active material seemed to enter more readily into solution at buffer mixtures of lower pH. To each sample, 1 cc. of saturated $\left(\mathrm{NH}_{4}\right)_{2} \mathrm{SO}_{4}$ was added. A cloudy suspension resulted which seemed to be somewhat more prominent in the acid media. All the fractions were kept on ice overnight. On the next day, a coarse, brown, doubly refractive precipitate was found to have formed in each of the samples.

The precipitates were separated, taken up in distilled water, and injected intracutaneously in rabbits to test for their effects on the permeability of small vessels. 
It was found that the greatest potency on the capillary wall was obtained from the material precipitated by ammonium sulfate at $\mathrm{pH} 7.8$. At lower $\mathrm{pH}$, the activity of the material was either absent or considerably reduced. Microscopic examination of the coarse precipitate obtained at $\mathrm{pH} 7.8$ by the addition of $\left(\mathrm{NH}_{4}\right)_{2} \mathrm{SO}_{4}$ revealed a yellowish crystalline meshwork, the pattern of which was somewhat reminiscent of the branched crystals recovered in the acetone-dried residue (Table I). The silver nitrate test indicated the presence of chlorides. These findings suggest that the active principle is so firmly associated with sodium chloride crystals that $\left(\mathrm{NH}_{4}\right)_{2} \mathrm{SO}_{4}$ precipitation per se seems to be incapable of dissociating and thus purifying further the active complex aggregate. This, as pointed out above, has been accomplished with relatively good results by prolonged butyl alcohol extractions.

8. Test for Proteins and Amino Acids.-The purified active substance yields a negative biuret reaction, indicating that it probably is not a protein. The Millon test is likewise negative. The xanthoproteic test is positive, indicating thus the presence of a benzene nucleus in an intermediary product of protein catabolism. The Adamkiewicz reaction is likewise positive, pointing to the probable presence of tryptophane. The ninhydrin test is positive. This supports the view that the active substance has at least one alpha-amino and one carboxyl group that are free. The reaction with lead acetate fails to reveal the presence of sulfur.

These various tests point directly to the view that the active permeability factor is not a protein but an intermediary product of proteolysis with free amino and carboxyl groups.

9. Proteolysis during Inflammation.-The occurrence of protein digestion in inflammatory exudates has been known for a long time. Mention of this phenomenon dates as far back as the ancient writers. The Corpus Hippocraticum regarded suppuration as the result of a special digestive mechanism termed coction. The products of proteolytic digestion in exudates were recognized by Eichwald in 1864, who reported what he thought was a peptone in pus. Friedrich Müller described the autolytic property of purulent exudates in tuberculosis and pneumonia. Opie has studied thoroughly the enzymatic property of cells of an exudate in digesting coagulated protein (18). According to him the ability of phagocytic cells to remove injurious material is dependent on the possession of proteolytic enzymes.

The end-products of proteolytic breakdown in exudates have been studied by us. The amino acid level was determined in samples removed from the inflamed pleural cavity of dogs. Parallel determinations were made on serum of blood withdrawn from the heart immediately following thoracentesis for the exudates. The colorimetric 
method of Folin (12) for the determination of amino nitrogen was employed throughout. About 0.2 to $0.5 \mathrm{cc}$. of exudate and of serum

TABLE II

Correlation between Amino Acid Level in Serum and Exudate and the Effect of the Latter on Capillary Permeability

\begin{tabular}{|c|c|c|c|c|c|}
\hline \multirow{2}{*}{ Dog. No. } & \multirow{2}{*}{$\begin{array}{l}\text { Duration of } \\
\text { inflammation }\end{array}$} & \multicolumn{2}{|c|}{ Amino acid nitrogen } & \multicolumn{2}{|c|}{$\begin{array}{l}\text { Accumulation of trypan blue in } \\
\text { skin areas treated with }\end{array}$} \\
\hline & & Blood serum & Exudate & Blood serum ${ }^{*}$ & Exudate \\
\hline $\begin{array}{l}1-04 \\
\text { Reinjected } 1.5 \text { cc. } \\
\text { turpentine on } 6 \text { th } \\
\text { day }\end{array}$ & $\begin{array}{c}\text { days } \\
1 \\
2 \\
3 \\
4\end{array}$ & \begin{tabular}{|c|} 
mg. per 100 cc. \\
5.35 \\
5.3 \\
2.9 \\
3.75
\end{tabular} & \begin{tabular}{|c|} 
mg. per 100 ce. \\
6.4 \\
6.5 \\
3.3 \\
4.75
\end{tabular} & $\begin{array}{c}+ \text { to }++ \\
+ \\
\text { Faint trace } \\
+\end{array}$ & $\begin{array}{l}++++ \\
+++ \\
+++ \\
++++\end{array}$ \\
\hline $\begin{array}{l}\text { 1-05 } \\
\text { Reinjected } 1.5 \text { cc. } \\
\text { turpentine }\end{array}$ & $\begin{array}{l}6 \\
8 \\
9\end{array}$ & $\begin{array}{l}7.8 \\
6.15 \\
\\
4.0 \\
5.25 \\
4.3\end{array}$ & $\begin{array}{l}6.05 \\
6.05 \\
5.35\end{array}$ & $\begin{array}{c}\text { Trace } \\
+\end{array}$ & $\begin{array}{c}\text { Trace to }+ \\
+ \\
+++ \\
++ \\
+\end{array}$ \\
\hline $1-06$ & $\begin{array}{l}1 \\
4 \\
5\end{array}$ & $\begin{array}{l}7.6 \\
3.6 \\
8.2\end{array}$ & $\begin{array}{c}6.1 \\
4.05 \\
12.25\end{array}$ & $\begin{array}{c}+ \\
\text { Trace } \\
\text { Trace to }+\end{array}$ & $\begin{array}{c}+ \\
+ \text { to }++ \\
+\end{array}$ \\
\hline $1-03$ & 5 & 6.4 & 9.2 & 0 & ++ \\
\hline Average..... & & 5.55 & 8.04 & & \\
\hline
\end{tabular}

* Cutaneous areas inoculated with serum invariably stained only the peripheral portion of the areas.

was injected each in the dermis of the abdomen of a rabbit. This was followed by the intravenous injection of trypan blue to determine the effect of these samples on the capillary wall. The results 
are summarized in Table II. The number of plus signs refers to the intensity of local cutaneous staining. The data indicate that the level of amino acid concentration in exudates was usually found somewhat higher than in serum. This state of affairs was correlated with the more pronounced effect of the exudate in increasing capillary permeability, as indicated by the intensity of the staining reaction.

On the other hand, a comparison of the total protein concentration in both exudate and serum was shown to follow a trend opposite to that of the amino acids. The total proteins of exudate and of serum were determined by the macro Kjeldahl method (13). It is clear from the data summarized in Table III, that the total protein concentration of exudates tends to be lower than that of blood serum. In other words, a comparison of the concentration of total proteins and amino acids in an inflammatory exudate with that in blood serum reveals an inverse type of reciprocal relationship. These facts confirm the observations of previous workers to the effect that proteolysis is very active in exudates, yielding numerous split products. That one of these, or perhaps a group of related compounds, may play an important rôle in the mechanism of increased capillary permeability seems a reasonable supposition. The available evidences support this view. The relative homogeneity of the active crystalline material recovered from exudates favors the idea of a single substance to explain the permeability phenomena. The possibility, however, of the existence in exudates of other active substances is not precluded by the data on hand. The present evidence merely indicates that there exists a factor in whole exudates which alters the normal permeability of capillaries. Analysis of the exudate reveals the presence of what appears to be a single crystalline substance which, per se, is capable of producing the same effect on the capillary wall as the whole exudate.

The positive tests for the presence of amino acids in the active permeability factor, coupled with the foregoing observations on increased proteolysis in exudates, indicated the necessity of determining the nitrogen content of the active crystalline substance. The analyses were carried out by the method of Wong (14) and of Folin and Denis (15) on small samples of the purified material. An appreciable 
amount of nitrogen was recovered, averaging 8.65 per cent (Table III).$^{6}$

In conclusion, the various tests outlined above, in addition to the apparent zwitterionic or dipolar ionic property of the permeability factor, the capacity of saturated ammonium sulfate and of 5 per cent phosphomolybdic acid (16) to precipitate it, and finally its diffusibility through a cellophane membrane, all suggest that the active crystalline substance may well be a relatively simple intermediary product of protein catabolism. It appears unlikely that it is a

TABLE III

Protein Nitrogen of Inflammatory Exudates

\begin{tabular}{|c|c|c|c|c|}
\hline \multirow{2}{*}{ Dog. No. } & \multirow{2}{*}{$\begin{array}{c}\text { Duration of in- } \\
\text { flammation }\end{array}$} & \multicolumn{2}{|c|}{ Protein } & \multirow{2}{*}{$\begin{array}{l}\text { Nitrogen content of } \\
\text { active crystalline } \\
\text { substance recovered } \\
\text { from an exudate }\end{array}$} \\
\hline & & Blood serum & Exudate & \\
\hline $6-3$ & $\begin{array}{c}d a y s \\
1 \\
2\end{array}$ & $\begin{array}{c}\text { gm. per } 100 \mathrm{cc} \text {. } \\
- \\
5.0\end{array}$ & $\begin{array}{c}\mathrm{gm} . \text { per } 100 \mathrm{cc} \\
4.6 \\
4.0\end{array}$ & gm. per $100 \mathrm{cc}$ \\
\hline $6-2$ & $\begin{array}{l}1 \\
2 \\
3 \\
4\end{array}$ & $\frac{6.4}{-}$ & $\begin{array}{l}5.1 \\
4.7 \\
5.4 \\
5.5\end{array}$ & $\begin{array}{l}8.1 \\
9.2\end{array}$ \\
\hline $6-1$ & $\begin{array}{l}1 \\
2 \\
4\end{array}$ & $\frac{-}{6.7}$ & $\begin{array}{l}4.3 \\
4.4 \\
-\end{array}$ & \\
\hline Average. & & 6.1 & 4.75 & 8.65 \\
\hline
\end{tabular}

proteose, a peptone, or an amino acid. The available data seem to indicate that this active substance probably belongs to the group of polypeptides. In a separate report observations will be presented indicating that a proteolytic enzyme, incubated with an otherwise relatively inactive blood serum, favors the formation of products that increase vascular permeability. These findings offer an additional

${ }^{6}$ In preliminary publication (4) the nitrogenous content was reported to average 2.3 per cent. This determination had been made on the active acetone-dried residue consisting of inorganic impurities with which the active material was probably associated. Further purification of the material by butyl alcohol has yielded correspondingly higher nitrogenous values. 
support concerning the general nature of the permeability factor. Further studies are being conducted, however, in an attempt to free the active crystalline substance completely of all impurities and to identify it chemically. This part of the work will form the subject of a future report. ${ }^{7}$

10. Is the Permeability Factor Related to Histamine?-Previous work had demonstrated that the permeability factor recovered from exudates, unlike histamine, fails to induce a contraction of the isolated intestine of a guinea pig (2). Other evidences failing to support the identity of the permeability factor and of histamine were described at the time and will therefore not be taken up again $(2,4)$. Suffice it to say that in the case of the isolated active crystalline substance extracted from exudates the same type of evidence was obtained. As shown in Text-fig. 1, the addition to the isolated intestinal segment of the active crystalline material fails to increase its contractility, whereas the subsequent administration of histamine induced a powerfully sustained tonic contraction. In brief, no evidence has as yet been obtained to support the view (3) that histamine or its presumably closely related $\mathrm{H}$ substance is identical with the permeability factor. ${ }^{8}$ The important additional property of the lat-

${ }^{7}$ In a preliminary paper (1) it was reported that the ashed material of an exu. date displays definite activity when in contact with normal capillaries. The accumulation of trypan blue, however, in such treated areas fails to exhibit the precise pattern of staining characteristic of the untreated exudate or of the isolated active material. Furthermore the possibility of an artefact is not ruled out, for it is to be remembered that ashing involves the conversion of a number of inorganic elements to their oxides, a condition which is quite different from their status in the untreated exudate.

${ }^{8} \mathrm{It}$ is interesting to note in this connection that butyl alcohol does not dissolve the basic amino acids, such as histidine. Histamine, which is decarboxylized histidine, is likewise insoluble in butyl alcohol. This is in sharp contrast to the active permeability factor which is distinctly soluble in butyl alcohol.

An additional chemical evidence that the factor is not histamine is furnished by the chemical test of Zimmermann with 1 per cent cobalt nitrate and $2 \mathrm{~N}$ sodium hydroxide solution (19). Histamine interacts with these reagents to form a specific violet color. The active material fails completely to induce any such color reaction, yielding merely a blue color followed almost immediately by the formation of a yellowish suspended precipitate.

Furthermore, experiments in progress indicate that the permeability factor fails to induce in the cat a lowering of blood pressure such as is elicited by histamine. 


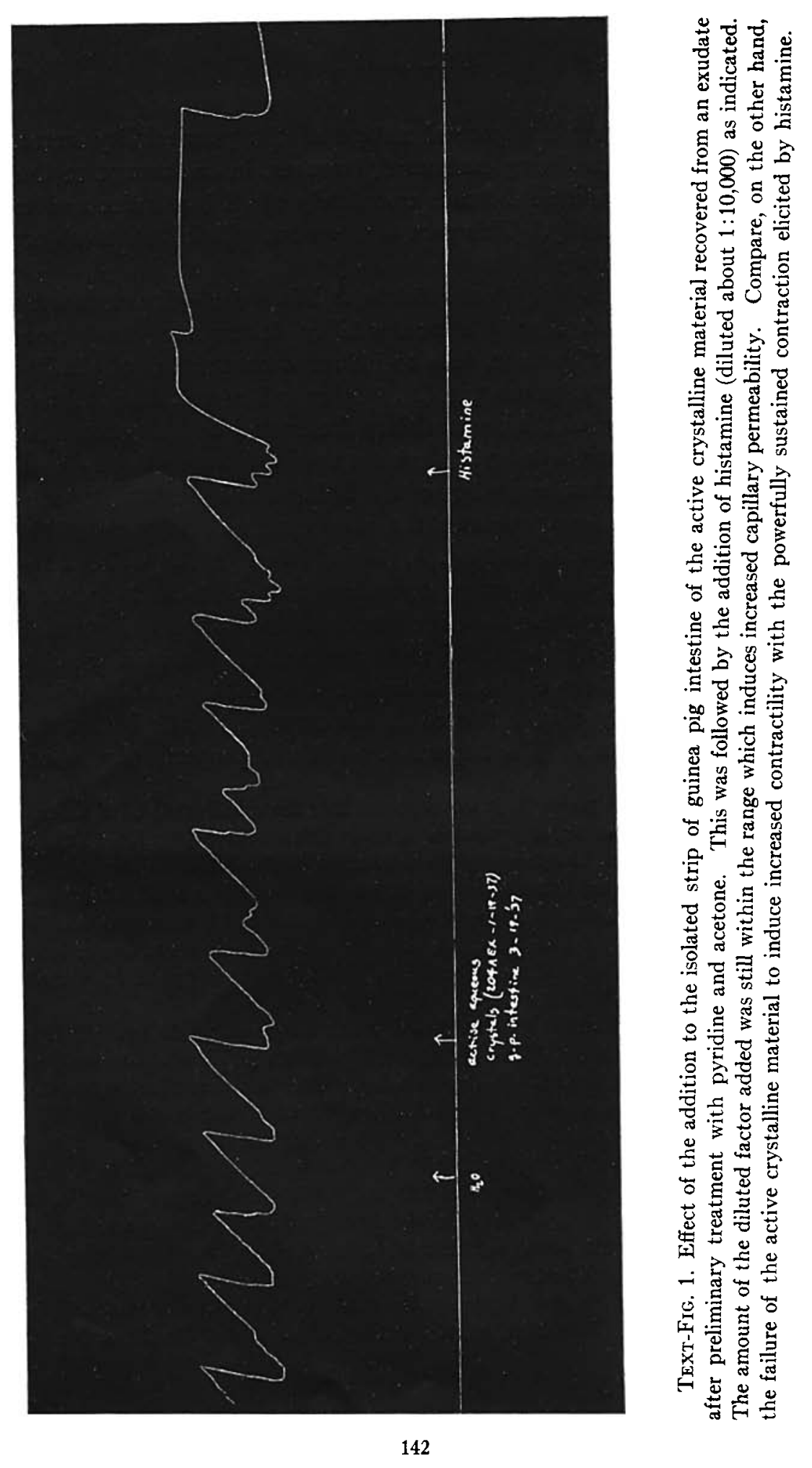


ter of inducing leukocytic migration will form the subject of a separate report (17). This chemotactic capacity is evidently not elicited by histamine (20).

\section{SUMMARY AND CONCLUSIONS}

There is present in inflammatory exudates a factor which induces a prompt increase in the permeability of normal capillaries. Its liberation and presence in exudates offers a reasonable explanation for the mechanism of increased permeability of small vessels in injured tissue.

A method for the isolation and purification of this permeability factor has been described. In its essential features, this consists of treating the exudate with pyridine followed by acetone. After separation of the protein fractions further purification can be obtained by prolonged extraction with butyl alcohol or by subjecting the acetone supernatant fraction to low temperature $\left(-20^{\circ} \mathrm{C}\right.$.). The latter favors spontaneous separation of the active principle. The purified material is a crystalline doubly refractive nitrogenous substance.

The factor is evidently not a protein, yet it contains amino and carboxyl groups. It gives a positive test for the presence of an indole nucleus in its structure (Adamkiewicz test). The active material is dialyzable; and it is precipitated by concentrated ammonium sulfate. The present evidence indicates that it is an intermediary breakdown product of protein metabolism, probably belonging to the group of relatively simple polypeptides. Further studies are being conducted in an endeavor to determine its precise chemical structure.

The technical assistance of Mr. M. Kadish and of Mrs. Charlotte R. Warner in the course of this investigation is appreciated.

\section{BIBLIOGRAPHY}

1. Menkin, V., Proc. Soc. Exp. Biol. and Med., 1936, 34, 570.

2. Menkin, V., J. Exp. Med., 1936, 64, 485.

3. Lewis, Sir T., The blood vessels of the human skin and their responses, London, Shaw and Sons Ltd., 1927.

4. Menkin, V., Proc. Soc. Exp. Biol. and Med., 1937, 36, 164.

5. Menkin, V., Arch. Path., 1937, 24, 65.

6. du Noüy, P. L., Equilibres superficiels des solutions colloidales, Paris, Masson et Cie, 1929. 
7. Butler, A. M., and Tuthill, E., J. Biol. Chem., 1931, 93, 171.

8. Dakin, H. D., Biochem. J., London, 1918, 12, 290.

9. Greenstein, J. P., J. Biol. Chem., 1937, 118, 321.

10. Harrow, B., and Sherwin, C. P., A text-book of biochemistry, Philadelphia, W. B. Saunders Co., 1935.

11. Northrop, J. H., Harvey Lectures, 1934-35, 30, 229.

12. Folin, O., J. Biol. Chem., 1922, 51, 377.

13. Peters, J. P., and Van Slyke, D. D., Quantitative clinical chemistry, Volume II. Methods, Baltimore, The Williams \& Wilkins Co., 1932.

14. Wong, S. Y., J. Biol. Chem., 1923, 55, 431.

15. Folin, O., and Denis, W., J. Biol. Chem., 1916, $26,473$.

16. Arthus, M., Precis de chimie, Paris, Masson et Cie, 1932.

17. Menkin, V., J. Exp. Med., 1938, 67, 145.

18. Opie, E. L., Arch. Int. Med., 1910, 5, 541.

19. Zimmermann, W., Z. physiol. Chem., 1930, 186, 260.

20. Moon, V., Arch. Path., 1935, 20, 561.

\section{EXPLANATION OF PLATE 3}

FIG. 1. High power drawing (about $\times 760$ ) of aggregates of doubly refractile granules recovered from an exudate after preliminary treatment with pyridine, acetone, and final purification with butyl alcohol (Table I). This material, taken up in distilled water and injected intracutaneously, induces increased capillary permeability and leukocytic migration.

FrG. 2. High power drawing (about $\times 760$ ) of needle-like crystals of the permeability factor. These crystals were obtained by gradually drying in a desiccator small amounts of the aqueous suspension of the material recovered after butyl alcohol purification (Fig. 1). These crystals taken up in distilled water, induce prompt increased capillary permeability followed by considerable leukocytic migration. 

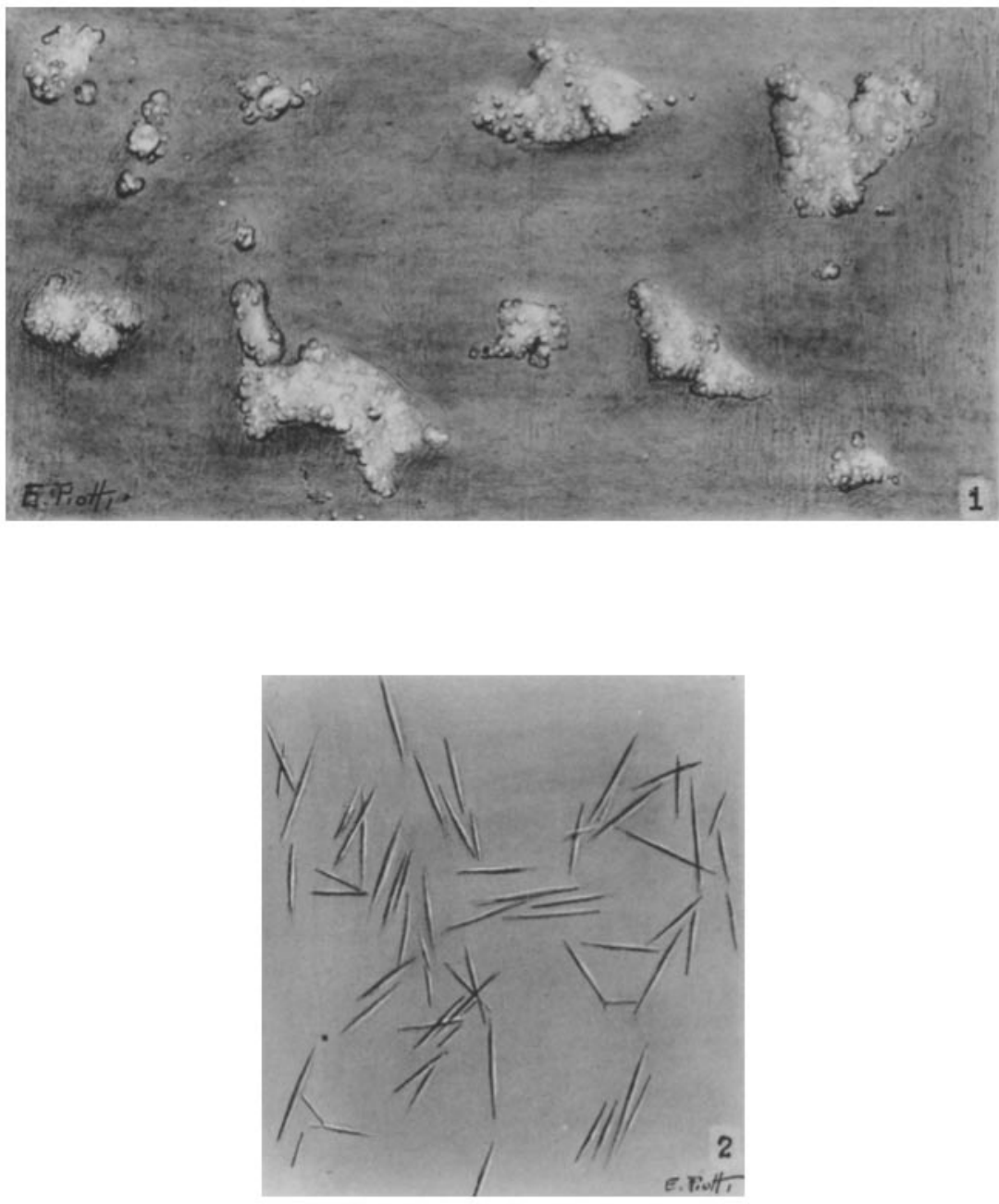

(Menkin: Studies on inflammation. XIV) 